\title{
Оцінювання рівня технічної підготовленості спортсменів 3 інвалідністю в карате
}

\author{
Ірина Когут, Вікторія Маринич, Катерина Чебанова
}

Національний університет фрізичного виховання і спорту України, Київ, Україна

Анотація. Аналіз практичного досвіду навчально-тренувальної роботи в карате, наукове обґрунтування результатів досліджень у сфері фрізичної культури та спорту, результати експертного оцінювання дозволили розробити навчальну програму з позашкільної освіти фрізкультурно-спортивного напряму «Карате - тренуємося разом», побудовану на основі інклюзивного підходу. Для визначення ефективності впровадження інклюзивного підходу до побудови навчально-тренувального процесу спортсменів 3 інвалідністю в карате проведено тестування, що включало два етапи (порівняльно-послідовний експеримент першого та другого порядків). Для оцінювання рівня технічної підготовленості спортсменів з інвалідністю було використано змагальні вправи з ката. Мета. Обґрунтувати структуру і зміст організаційно-методичного забезпечення навчально-тренувального процесу (технічної підготовленості) спортсменів з інвалідністю в карате. Методи. Аналіз і узагальнення спеціальної науково-методичної літератури, документальних матеріалів та матеріалів мережі Інтернет; педагогічне спостереження; вимірювання; методи математичної статистики. Результати. По завершенні експериментального дослідження, у спортсменів з інвалідністю було виявлено достовірні відмінності за всіма досліджуваними параметрами технічної підготовленості. Показники тесту технічної підготовленості, а саме виконання ката хейаншодан покращились на 4,2 \%. Організація та проведення навчально-тренувальних занять $€$ ефективними за умови правильно підібраних організаційно-методичних рекомендацій до реалізації навчально-тренувального процесу.

Ключові слова: карате, ката, спортсмени 3 інвалідністю, технічна підготовленість,

навчально-тренувальний процес, організаційно-методичне забезпечення.

\section{Iryna Kogut, Viktoriia Marynych, Kateryna Chebanova}

\section{ASSESSMENT OF THE TECHNICAL PREPAREDNESS OF DISABLED ATHLETES IN KARATE}

Abstract. An analysis of practical experience of educational training work in Karate, scientific substantiation of the results of the study in the field of physical culture and sports, and the results of expert evaluation allowed to develop the extracurricular training program in physical culture and sports «Karate - let's train together» based on an inclusive approach. To identify the effectiveness of the implementation of an inclusive approach to the programming the training process of disabled athletes in karate, the testing was conducted, which included two stages (comparative and sequential experiment of the first and second orders). To assess the level of technical preparedness of disabled athletes, competitive katas were done. Objective. To substantiate the structure and content of organizational and methodological support of the educational and training process (technical preparedness) of disabled athletes in karate. Methods. Analysis and generalization of special scientific and methodological literature, documentary materials, and materials of the Internet; pedagogical observation; measurement; and methods of mathematical statistics. Results. At the end of the experimental study, disabled athletes were found to have significant differences in all studied parameters of technical preparedness. The performance of the technical preparedness test, i.e., the performance of the Heian-Shodan kata, improved by $4,2 \%$. The organization and conduct of training sessions are effective when the proper organizational and methodological recommendations are provided for the implementation of the training process.

Keywords: Karate, kata, disabled athletes, technical preparedness, educational training process, organizational and methodological support.

Kogut I., Marynych V., Chebanova K. Assessment of the technical preparedness of disabled athletes in karate Theory and Methods of Physical education and sports. 2021; 3: 32-36 DOI: $10.32652 /$ tmfvs.2021.3.32-36
Когут І., Маринич В., Чебанова К. Оцінювання рівня технічної підготовленості спортсменів 3 інвалідністю в карате. Теорія і методика фрізичного виховання і спорту. 2021; 3 : 32-36

DOI: 10.32652/tmfvs.2021.3.32-36 on Prepubertal Tennis Players. Journal of strength and conditioning research. 2019;33(3):651-661.

Надійшла 20.09.2021

Вступ. Навчально-тренувальний процес в карате, побудований на застосуванні інклюзивного підходу, має свою складну і розгалужену систему методів і засобів та залежить від багатьох факторів, таких як програма змагань, мета та завдання тренування, рівень квалісрікації спортсмена, спортивна класифікація (нозологічна група) тощо [3, 7, 10, 14]. Побудова тренування (принципи, методи, засоби) та спортивні навантаження в карате різняться залежно від програми змагань. Зокрема в ката методика підготовки спортсменів з інвалідністю розробляється, ґрунтуючись на знаннях спеціалістів 3 реабілітації, лікарів та тренерів 3 карате [8, 9, 15, 19]. Відповідно до діагнозу та специфріки захворювання спортсменів, засоби та методи підготовки постійно доповнюються та змінюються $[4,5,17,18]$. Аналіз літератури, узагальнення власного досвіду та експертне опитування спеціалістів сфери фрізичної культури та спорту дозволили виявити базові положення організації тренувального процесу: структуру, тривалість, періодичність занять та етапи підготовки спортсменів [12, 13, 16, 20].

Роботу виконано в рамках теми 1.7. «Організаційно-методичні основи розвитку адаптивного спорту» тематичного плану науково-дослідної роботи в сфрері фізичної культури і спорту на 2016-2020 рр. Міністерства освіти і науки України (номер держреєстрації 0116U001613).

Мета дослідження - обґрунтувати структуру і зміст організаційно-методичного забезпечення навчальнотренувального процесу спортсменів 3 інвалідністю в карате.

Методи дослідження: аналіз і узагальнення спеціальної науково-методичної літератури, документальних матеріалів та матеріалів мережі Інтернет; тестування, педагогічне спостере- 
ження; вимірювання; методи математичної статистики.

Результати дослідження та їх обговорення. В експерименті брали участь спортсмени 14-20 років з інвалідністю в кількості 10 осіб (п'ять дівчат і п'ять хлопців), які мають дитячий церебральний параліч, затримку фрізичного розвитку та аутизм. Спортсмени та їхні батьки були інсрормовані про всі особливості дослідження і дали згоду на участь в експерименті. 3 метою опрацювання наукових матеріалів застосовували методи математичної статистики для кількісного аналізу отриманих результатів. Обробку результатів проводили за допомогою «Excel 2016» (Microsoft, США). Протокол дослідження був затверджений Центром соціально-психологічної реабілітації дітей та молоді 3 фрункціональними обмеженнями Дарницького району.

Під час дослідження спортсмени виконували ката хейан-шодан у першому та другому періодах порівняльно-послідовного експерименту.

Усі спортсмени, які брали участь у дослідженні, на початок експерименту (перший період) мали необхідний рівень майстерності, тобто вміли виконувати ката хейан-шодан. Для удосконалення рівня технічної підготовки вони займались за розробленою програмою «Карате - тренуємося разом» [11]. У ході експерименту іспитованим було запропоновано систематично виконувати кілька вправ, а саме:

1) ой-цукі чудан з переміщенням вперед у стійці дзенкуцу-дачі (прямий удар у кроці однойменною рукою в корпус);

2) гедан-барай 3 переміщенням вперед у стійці дзенкуцу-дачі (нижній блок від прямих ударів ногами);

3) аге-уке з переміщенням вперед у стійці дзенкуцу-дачі (верхній блок від ударів по голові зверху вниз);

4) шуто-уке 3 переміщенням вперед у стійці кокуцу-дачі (середній блок від прямих ударів руками та ногами).

Ката хейан-шодан - це перше 3 п'яти базових ката в карате [1, 2]. Загалом складається 321 руху, серед яких зустрічаються блоки: гедан-барай, аге-уке і шуто-уке; удари: ой-цукі чудан, тетсуі-учі дзьодан і шуто-учі. В

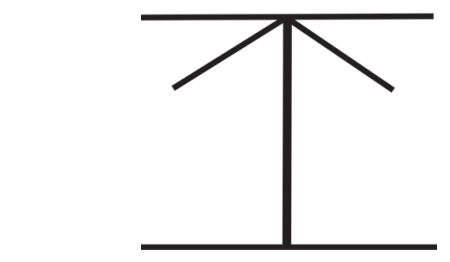

Рисунок 1 - Схема виконання ката хейаншодан

ката $€$ техніка визволення від захвату супротивником зап'ястя та відхід 3 лінії атаки (тай-сабакі). Хейан-шодан спрямований на відпрацювання основ базової техніки та формує фрундамент для розвитку координації рухів і орієнтації у просторі. В хейан-шодан $€$ два кіай: перший - під час виконання останнього аге-уке в кінці першої доріжки, другий - під час виконання останнього ой-цукі чудан в кінці другої доріжки. Загалом на виконання ката відведено 40 с (рис. 1).

Послідовність виконання технічних дій в ката хейан-шодан [6]:

1. Поворот вліво, крок лівою ногою вперед в дзенкуцу-дачі, геданбарай лівою рукою.

2. Крок вперед правою ногою в дзенкуцу-дачі, ой-цукі.

3. Розворот на $180^{\circ}$ вправо з кроком правою ногою в дзенкуцу-дачі, гедан-барай правою рукою.

4. Вивільнення від захвату за руку коловим рухом руки з перенесенням ваги тіла назад і контратака боковою стороною кулака (тетсуі-учі).

5. Крок вперед лівою ногою в дзенкуцу-дачі, ой-цукі.

6. Поворот на $90^{\circ}$ вліво з кроком лівою ногою в дзенкуцу-дачі, геданбарай лівою рукою.

7. Крок вперед правою ногою в дзенкуцу-дачі, аге-уке правою рукою.

8. Крок вперед лівою ногою в дзенкуцу-дачі, аге-уке лівою рукою.

9. Крок вперед правою ногою в дзенкуцу-дачі, аге-уке правою рукою. Кіай.

10. Розворот на $270^{\circ}$ вліво 3 кроком лівою ногою в дзенкуцу-дачі, гедан-барай лівою рукою.

11. Крок вперед правою ногою в дзенкуцу-дачі, ой-цукі.

12. Розворот на $180^{\circ}$ вправо $з$ кроком правою ногою в дзенкуцу-дачі, гедан-барай правою рукою.
13. Крок вперед лівою ногою в дзенкуцу-дачі, ой-цукі.

14. Поворот на $90^{\circ}$ вліво з кроком лівою ногою в дзенкуцу-дачі, геданбарай лівою рукою.

15. Крок вперед правою ногою в дзенкуцу-дачі, ой-цукі.

16. Крок вперед лівою ногою в дзенкуцу-дачі, ой-цукі.

17. Крок вперед правою ногою в дзенкуцу-дачі, ой-цукі. Кіай.

18. Розворот на $270^{\circ}$ вліво в кокуцу-дачі, шуто-уке лівою рукою.

19. Крок правою ногою під $45^{\circ}$ вправо в кокуцу-дачі, шуто-уке правою рукою.

20. Поворот на $135^{\circ}$ вправо кроком правою ногою в кокуцу-дачі, шуто-уке правою рукою.

21. Крок лівою ногою під $45^{\circ}$ вправо, в кокуцу-дачі шуто-уке лівою рукою.

Під час проведення порівняльнопослідовного експерименту першого порядку спортсмени виконували запропоновані вправи під рахунок тренера. Кожну вправу виконували в русі та на 10 рахунків. Щоб покращити техніку виконання ката хейаншодан, іспитовані спортсмени вивчили стійки дзенкуцу-дачі та кокуцу-дачі на місці та в русі. У ході вивчення стійки дзенкуцу-дачі вони допускали такі помилки: відривали п'яту задньої ноги, згинали задню ногу, неправильно обирали точку опори, занадто нахиляли вперед (назад) корпус, розташовували ноги на одній лінії. Під час виконання стійки кокуцу-дачі були допущені такі помилки: занадто згинали коліно передньої ноги, неправильно розташовували ступні обох ніг, занадто завантажували передню ногу (неправильно обирали центр маси тіла).

Для того щоб засвоїти техніку переміщення в стійках дзенкуцу-дачі та кокуцу-дачі, спортсмени тренувались стояти в них і переміщатися мінімум один раз на тиждень протягом всього періоду експерименту.

Крім стійок, спортсмени на кожному тренуванні виконували удар ойцукі та блоки - гедан-барай, аге-уке і шуто-уке. Блоки й удари виконували в три етапи: 
Т а б л и ц я 1. Зменшення початкової оцінки за виконання ката

\begin{tabular}{|c|c|c|}
\hline № $3 / n$ & Груба помилка, 1 бал & Незначна помилка, 0,5 бала \\
\hline 1 & $\begin{array}{l}\text { Відхилення в техніці виконання } \\
\text { (неправильний рівень удару) }\end{array}$ & $\begin{array}{l}\text { Неправильний темп виконання ката } \\
\text { (занадто повільний, або швидкий) }\end{array}$ \\
\hline 2 & $\begin{array}{l}\text { Відсутність кіай, або його виконання } \\
\text { не на тому елементі }\end{array}$ & Одноразова помилка у виконанні стійки \\
\hline 3 & $\begin{array}{l}\text { Відступ від початкового місця почат- } \\
\text { ку ката більше ніж на } 1 \text { м }\end{array}$ & $\begin{array}{l}\text { Незначні помилки в техніці виконання } \\
\text { (положення рук, ніг) }\end{array}$ \\
\hline 4 & Втрата рівноваги & $\begin{array}{l}\text { Незначний відступ від початкового місця } \\
\text { початку ката }\end{array}$ \\
\hline 5 & $\begin{array}{l}\text { Неправильні стійки (занадто високі, } \\
\text { широкі, вузькі і т.д.) }\end{array}$ & Відривання п'яток при переміщеннях \\
\hline
\end{tabular}

Т а б л и ц я 2. Збільшення початкової оцінки за виконання ката

\begin{tabular}{|l|l|}
\multicolumn{1}{|c|}{ Критерій } & \multicolumn{1}{c|}{ 3міст } \\
\hline $\begin{array}{l}\text { Правильність виконання } \\
\text { технічних елементів }\end{array}$ & $\begin{array}{l}\text { 1. Правильне виконання стійок, блоків та ударів в } \\
\text { поєднанні з заншином. } \\
\text { 2. Відсутність зайвих рухів. } \\
\text { 3. Точне та правильне перенесення центру маси тіла і } \\
\text { 3береження рівноваги }\end{array}$ \\
\hline $\begin{array}{l}\text { Вміння змінювати швидкість } \\
\text { виконання технічних } \\
\text { елементів }\end{array}$ & $\begin{array}{l}\text { 1. Збільшення чи зменшення швидкості рухів, коли це } \\
\text { необідно. } \\
\text { 2. Виконання технічних дій у темпі, який є правильним } \\
\text { відносно бункаю ката }\end{array}$ \\
\hline $\begin{array}{l}\text { Вміння працювати з розслаб- } \\
\text { ленням та напруженням } \\
\text { м'язів }\end{array}$ & $\begin{array}{l}\text { 1. Можливість проявляти необхідний рівень сили. } \\
\text { 2. Розслаблення м'язів у ті моменти, коли це необхідно }\end{array}$ \\
\hline $\begin{array}{l}\text { Вміння працювати з правиль- } \\
\text { ним диханням }\end{array}$ & $\begin{array}{l}\text { 1. Правильне та своєчасне застосування спеціальних } \\
\text { технік дихання (ібукі) і бойових вигуків (кіай). } \\
\text { 2. Підтримання правильного дихання відповідно до ви- } \\
\text { конуваних технічних дій }\end{array}$ \\
\hline
\end{tabular}

1. Імітаційні вправи: виконання блоків на ударів без партнера (перед дзеркалом).

2. Кіхон: вивчення техніки спочатку на місці, потім з переміщенням.

3. Виконання техніки 3 партнером (спортсмен 3 інвалідністю у парі 3 практично здоровим однолітком). По черзі працюють першим та другим номером, відпрацьовуючи на практиці як удари та блоки, так і переміщення.

Отже, успішність виконання ката хейан-шодан залежить від таких факторів:

- розуміння техніки та відповідне виконання деяких базових технічних дій (гедан-барай, аге-уке, шуто-уке, ой-цукі);

- знання базових стійок (дзенкуцу-дачі, кокуцу-дачі) та уміння переміщатися в них;
- знання бункаю (аналізу) ката;

- заншин, кіме, кіай (стан повної концентрації уваги та сили, готовності до дій).

Під час виконання змагальних вправ спортсмени виконували ката хейан-шодан. По одному виходили на татамі та виконували ката. Оцінку виставляв тренер та чотири старші спортсмени. Всього каратист отримував п'ять оцінок, під час розрахунку остаточного бала за виконання ката найвищий і найнижчий бали 3 двох оцінок не враховувалися.

Критеріями оцінювання ката є: правильність виконання технічних елементів (блоки, удари, стійки); збереження рівноваги; заншин; кіме; кіай; загальний рівень демонстрації ката.

Початкова оцінка перед виходом на татамі - 7 балів. Після виконання ката початкова оцінка або знижувалася за допущені помилки (табл. 1), або підвищувалась за високу майстерність виконання (табл. 2).

За допущення деяких грубих помилок спортсменів дискваліфрікують. Дискваліфрікація може бути в таких випадках: незнання рисунка ката; порушення послідовності рухів; заміна елемента; демонстрація не того ката, яке назвав сам спортсмен; неспортивна поведінка. Наших іспитованих під час експерименту не дискваліфікували, проте вони мали значне зниження балів при допущенні зазначених помилок.

Збільшення початкової оцінки може відбуватися на 0,5 бала, якщо спортсмен дотримується таких критеріїв (див. табл. 2).

у ході проведення тестування порівняльно-послідовного експерименту першого порядку спортсмени виконали ката хейан-шодан та отримали свої бали (табл. 3). Важливо зазначити, що виконання хейан-шодан на даному етапі показало, що спортсмени мають середній технічний рівень (середній загальний бал - 17). Більшість допустили одну грубу помилку (переважно це було нанесення ударів по невідповідному рівню та втрата рівноваги через неправильні стійки, які були або занадто високими, або положення ступні не відповідало правильному). Майже у всіх спортсменів були наявні незначні помилки, такі як відривання п'яток під час переміщення та неправильний темп виконання ката (виконували його занадто швидко). Важливо зазначити, що рисунок ката знали всі іспитовані спортсмени і виконали його без замін елементів та повністю від початку до кінця, хоча і не всі завершили його в точці початку (що є помилкою).

Під час проведення порівняльнопослідовного експерименту другого порядку спортсмени повторно виконали ката хейан-шодан та отримали відповідні результати (див. табл. 3).

Важливо зазначити, що в ході виконання не було допущено грубих помилок. Спортсмени показали високий рівень демонстрації ката, виконали його 3 кіме та кіай, темп виконан- 
Т а б л и ц я 3. Оцінки за виконання ката під час експерименту

\begin{tabular}{|c|c|c|c|c|c|c|}
\hline \multirow[t]{2}{*}{ Спортсмен } & \multicolumn{6}{|c|}{ Оцінка, бал } \\
\hline & 1 & 2 & 3 & 4 & 5 & Разом \\
\hline \multicolumn{7}{|c|}{ Перший порядок } \\
\hline Д. М. & 5,5 & 5,7 & 5,4 & 5,5 & 5,6 & 16,6 \\
\hline Ю. B. & 5,6 & 5,6 & 5,5 & 5,6 & 5,7 & 16,8 \\
\hline H. B. & 5,7 & 5,6 & 5,6 & 5,5 & 5,4 & 16,7 \\
\hline Б. 0. & 5,8 & 5,8 & 5,7 & 5,6 & 5,6 & 17,1 \\
\hline M. A. & 5,8 & 5,7 & 5,8 & 5,5 & 5,4 & 17,0 \\
\hline Д. Д. & 5,6 & 5,7 & 5,6 & 5,4 & 5,6 & 16,8 \\
\hline Ш. 0. & 5,7 & 5,8 & 5,6 & 5,9 & 6,0 & 17,4 \\
\hline C. A. & 5,8 & 5,7 & 5,5 & 6,0 & 5,9 & 17,4 \\
\hline Ф. 0. & 5,6 & 5,8 & 5,6 & 5,7 & 6,0 & 17,1 \\
\hline C. K. & 5,9 & 5,7 & 5,8 & 5,6 & 5,5 & 17,1 \\
\hline \multicolumn{7}{|c|}{ Другий порядок } \\
\hline Д. М. & 5,7 & 5,9 & 5,7 & 5,8 & 5,9 & 17,4 \\
\hline Ю. B. & 5,8 & 5,8 & 5,7 & 5,9 & 5,8 & 17,4 \\
\hline H. B. & 5,9 & 5,7 & 5,8 & 5,7 & 5,9 & 17,4 \\
\hline Б. 0. & 6,0 & 6,1 & 6,0 & 5,9 & 5,9 & 17,9 \\
\hline M. A. & 6,0 & 6,0 & 5,9 & 5,9 & 5,8 & 17,8 \\
\hline Д. Д. & 5,8 & 5,8 & 5,7 & 5,6 & 5,9 & 17,3 \\
\hline Ш. 0. & 6,1 & 6,1 & 6,2 & 6,0 & 5,9 & 18,1 \\
\hline C. A. & 6,1 & 6,0 & 6,0 & 6,3 & 5,9 & 18,1 \\
\hline Ф. 0. & 5,9 & 5,8 & 6,0 & 6,0 & 6,1 & 17,9 \\
\hline C. K. & 5,8 & 5,9 & 5,9 & 6,1 & 6,0 & 17,8 \\
\hline
\end{tabular}

ня був правильний. Це свідчить про те, що заняття за розробленою програмою вплинули на підвищення рівня оволодіння базовою технікою. Спортсмени змогли показати подібний рівень саме завдяки правильним стійкам (збереження рівноваги, точне перенесення центру маси тіла), правильному темпу та прояву необхідного рівня сили.

Висновки. Експериментальна перевірка навчальної програми 3 позашкільної освіти фрізкультурноспортивного напряму «Карате - тренуємося разом», побудована на інклюзивному підході, продемонструвала позитивні зміни показників рівня технічної підготовленості осіб 3 інвалідністю. Під час проведен- свідчить про правильність підібраних вправ і методик у програмі, про адекватність навантаження та доцільність використання запропонованої методики під час роботи з особами з інвалідністю (зокрема 3 діагнозом ДЦП, ЗФР та аутизм).

Конфлікт інтересів. Автори заявляють, що відсутній будь-який конфолікт інтересів.

\section{ЛІТЕРАТУРА:}

1. Аксенов Э. Каратэ: от белого пояса к черному. Традиционная техника и приемы уличной самозащиты. Litres, 2019.

2. Ашанин ВС, Литвиненко АН. Индивидуализация технической подготовки квалифицированных каратистов. Физическое воспитание студентов. 2011;(1):7-10.

3. Баранов МВ. Классификационные признаки техники каратэ-до. Слобожанський науково-спортивний вісник.2010;(3):67-70.

4. Глухов СТ, Лукавенко АВ, Усков СВ Религиозно-философсккие основы учебновоспитательного процесса боевых искусств Дальнего Востока. Проблемы современного педагогического образования. 2018;58:1.

5. Завальнюк 0. Спорт як чинник становлення морально-вольових якостей особистості. Вісник Інституту розвитку дитини. 2014;35:3641.

6. Заулошнов В. Использование метода идеомоторной настройки для повышения надежности выполнения технических комплексов ката в каратэ-до. Молода спортивна наука України. 2013;17(1).79-82.

7. Когут ИА, Маринич ВЛ. Организационное обеспечение физкультурно-оздоровительной работы со студенческой молодежью во внешкольных учебных заведениях. Физическое воспитание студентов. 2016;(4):1223. DOI: $10.15561 / 20755279.2016 .0402$

8. Когут I0, Маринич ВЛ, Чебанова КВ Еволюція ката на візках: від Асаї Сенсея до Паралімпійських ігор. Молодь та олімпійський рух: зб. тез доповідей X Міжнар. конф.; 2017. 24-25 травня. Київ. НУФВСУ: 2017:208-210.

9. Когут І0, Маринич ВЛ, Чебанова КВ. Підготовка спортсменів 3 інвалідністю для участі у змаганнях з карате у розділі «Ката». Фізична активність і якість життя людини: зб. тез доп. II Міжнар. наук.-практ. конф; 2019 11-13 червня. Луцьк. Східноєвроп. нац. ун-т ім. Лесі Українки; 2019:83.

10. Когут I, Маринич В, Чебанова К. Методологічне та методичне забезпечення організації інклюзивного навчальнотренувального процесу спортсменів 3 інвалідністю в карате. Теорія та методика фріз. виховання. 2021;21(2):121-128. DOI: 10.17309/ tmfv.2021.2.04.

11. Навчальна програма 3 позашкільної освіти фізкультурно-спортивного напряму «Карате - тренуємося разом» (авт. Когут I0, Маринич ВЛ, Чебанова КВ) «Схвалено для використання в позашкільних навчальних закладах» (протокол засідання науково-методичної комісії з позашкільної освіти Науково-методичної ради з питань освіти МОН України від 26.062019 № 2; лист ІМ30 від 08.07.2019 № 22.1/12-Г-588)

12. Накаяма М. Практическое каратэ для всех. Москва: ФАИР-ПРЕСС, 2002. 286 с. 
13. Накаяма М. Динамика каратэ. Москва: ФАИР-ПРЕСС, 2003. 300 c

14. Ben Messaud W. Karate, and the perception of the sport. Ido Movement for Culture. Journal of Martial Arts Anthropology. 2016;16(3):47-56. DOI 10.14589/ido.16.3.6

15. Cazee C. Ensuring Access for Individuals with Disabilities In Sporting Activities: Sports for all. 2020

16. Conant K, Morgan A, Muzykewicz D, et al A karate program for improving self-concept and quality of life in childhood epilepsy: Results of a pilot study. Epilepsy \& Behavior. 2008;12(1):61 65. D0I: 10.1016/j.yebeh.2007.08.011

17. Greco G, Cataldi S, Fischetti F. Karate as anti-bullying strategy by improvement resilience and self-efficacy in school-age youth. Journal of Physical Education and Sport. 2019:1863-1870. DOI:10.7752/jpes.2019.s5276

18. Greco, Gianpiero, et al. Effects of Shotokan Karate on resilience to bullying in adolescents 2019. D0I:10.14198/jhse.2019.14.Proc4.52

19. Koropanovski N. Anthropometric and physical performance profiles of elite karate kumite and kata competitors. Journal of human kinetics. 2011:107. DOI: 10.2478/v10078-011-0078-X

20. Yip, Yick Hong. The effect of Karate training on the stereotypic behaviour, social interaction and communication of the children with Autism Spectrum Disorder. Diss. Hong Kong: Hong Kong Shue Yan University. 2019. D0I:10.7752 jpes.2020.04223

\section{LITERATURE}

\section{ІНФОРМАЦІЯ ПРО АВТОРІВ}

Когут Ірина Олександрівна https:orcid.org/0000-0002-8862-9545, kogut_irina@ukr.net Маринич Вікторія Леонідівна https:orcid.org/0000-0003-2784-680X, wikleon@ukr.net Чебанова Катерина Вікторівна https:orcid.org/0000-0003-4601-2130, jkasniper@gmail.com Національний університет фізичного виховання і спорту України 03150, Київ, вул. Фізкультури, 1

\section{INFORMATION ABOUT THE AUTHORS}

Kogut Iryna https:orcid.org/0000-0002-8862-9545, kogut_irina@ukr.net Marynych Viktoriia https:orcid.org/0000-0003-2784-680X, wikleon@ukr.net Chebanova Kateryna https:orcid.org/0000-0003-4601-2130, jkasniper@gmail.com

National University of Ukraine on Physical Education and Sport 03150, Kyiv, Fizkul'tury str., 1.
Proc. of the II Internat. scient.-pract. conf.; 2019, June 11-13. Lutsk. Lesya Ukrainka East European National University; 2019:83.

10. Kogut I, Marynych V, Chebanova K. Methodological and methodical support for the organization of inclusive educational and training process of disabled athletes in karate. Theory and methodology of physical education. 2021;21(2):121-128. DOI: 10.17309/tmfv. 2021.2.04

11. Extracurricular training program in physical culture and sports "Karate - let's train together" (auth. by Kogut IO, Marynych VL, Chebanova KV) "Approved for the use in out-ofschool educational institutions" (Minutes of the meeting of the scientific-methodical commission on out-of-school education of the Scientificmethodical Council for Education of the Ministry of Education and Science of Ukraine on 26.062019 No. 2; Letter of the Institute of education content modernization on 08.07.2019 No. 22.1/12-G-588).

12. Nakayama M. Practical Karate for everyone. Moscow: FAIR-PRESS, 2002. 286 p.

13. Nakayama M. Dynamics of Karate. Moscow: FAIR-PRESS, 2003. 300 p

14. Ben Messaud W. Karate, and the perception of the sport. Ido Movement for Culture. Journal of Martial Arts Anthropology. 2016;16(3):47-56. DOI: 10.14589/ido.16.3.6

15. Cazee C. Ensuring Access for Individuals with Disabilities In Sporting Activities: Sports for all. 2020

16. Conant K, Morgan A, Muzykewicz D, et al. A karate program for improving self-concept and quality of life in childhood epilepsy: Results of a pilot study. Epilepsy \& Behavior. 2008;12(1):6165. DOI: 10.1016/j.yebeh.2007.08.011

17. Greco G, Cataldi S, Fischetti F. Karate as anti-bullying strategy by improvement resilience and self-efficacy in school-age youth. Journal of Physical Education and Sport. 2019:1863-1870. DOI:10.7752/jpes.2019.s5276

18. Greco, Gianpiero, et al. Effects of Shotokan Karate on resilience to bullying in adolescents. 2019. DOI:10.14198/jhse.2019.14.Proc4.52

19. Koropanovski N. Anthropometric and physical performance profiles of elite karate kumite and kata competitors. Journal of human kinetics. 2011:107. DOI: 10.2478/v10078-011-0078-X

20. Yip, Yick Hong. The effect of Karate training on the stereotypic behaviour, social interaction and communication of the children with Autism Spectrum Disorder. Diss. Hong Kong: Hong 